\title{
CROHN'S DISEASE OR INTESTINAL TUBERCULOSIS: A DIAGNOSTIC DILEMMA
}

Amit Dashputra ${ }^{1}$, Ira Shah ${ }^{2}$.

${ }^{1}$ Seth G S Medical College, Mumbai, India

2Pediatric Gastroenterology and Infectious Diseases, Levioza Health Care, Mumbai, India

\section{Clinical Problem}

A 12-year-old boy presented with pain in the abdomen for 5 months and a weight loss of $18 \mathrm{~kg}$ in the same period. He used to pass non-bloody loose stools with mucus 2-3 times a day. The examination showed tenderness over the entire abdomen. Investigations showed hemoglobin $9.6 \mathrm{~g} / \mathrm{dL}$, white blood cell count $9000 /$ cumm (56\% polymorphs, $40 \%$ lymphocytes), platelets 9,88,000/cumm, ESR $32 \mathrm{~mm}$ at end of 1 hour. Stool examination showed $40-50$ pus cells/HPF and 18-20 red blood cells/HPF. Fecal Calprotectin was more than $800 \mu \mathrm{g} / \mathrm{mg}$. A colonoscopy revealed ulcers in the sigmoid colon, transverse colon, ascending colon, ileocaecal valve, caecum, and terminal ileum. Histopathology of the ileocaecal biopsy showed surface ulcerations, moderate lymphoplasmacytic, as well as neutrophilic, infiltrate with multinucleated giant cells and occasional granulomas. Colonic mucosa had multinucleated giant cells and acid-fast staining was negative. Quantiferon TB Gold and tuberculin skin test (TST) was negative. ANA was negative.

How to differentiate between Crohn's disease and intestinal tuberculosis?

\section{Discussion}

Diagnosing inflammatory bowel disease (IBD) poses two major problems. One is a lack of gold standard represented by histological or serological confirmation; second is the number of conditions mimicking IBD. Tuberculosis (TB) and Crohn's disease (CD) have different etiologies, the former being an infectious disease, and the latter an immune-mediated condition because of a complex interaction between genetic and environmental factors. However, they share several immunopathogenic features. ${ }^{1}$ The immunopathogenetic link between Mycobacterium tuberculosis (MTB) infection and $C D$ has been only partially elucidated. ${ }^{2}$ Children with $C D$ or intestinal TB may present with symptoms of obstruction, pain, or a palpable mass in the right iliac fossa. Intestinal perforation is a possible complication of $C D$ and, more rarely, of intestinal TB. ${ }^{3}$ On endoscopy, transversely placed ulcers, nodularity, hypertrophic lesions, the involvement of fewer than four segments, a patulous ileocecal valve are frequent in TB. Aphthoid or longitudinal deep fissuring ulcers and cobblestone

\section{CONTACT Amit Dashputra}

Email: amitdashputra@outlook.com

Address for Correspondence: Amit Dashputra, Seth G S Medical College, Mumbai, India.

(C)2019 Pediatric Oncall

\author{
ARTICLE HISTORY \\ Received 1 January 2019 \\ Accepted 7 February 2019 \\ KEYWORDS \\ Intestinal granuloma, TB, IBD
}

appearance are more typical of CD. Skip lesions in the colon are significantly frequent in $C D .{ }^{4}$ On histopathology, caseation, and demonstration of AFB, the diagnostic feature of TB are found in only $18-33 \%$. Features that favor a diagnosis of CD include infrequent $(<5)$, small $(<200 \mu)$ granulomas that are poorly organized, discrete or isolated. ${ }^{5}$ Average calprotectin levels between 50 and $300 \mu \mathrm{g} / \mathrm{mg}$ are associated with numerous intestinal diseases and drugs (e.g. NSAIDs, alcohol) and associated with low-grade intestinal inflammation. However, only untreated IBD and certain food infections are associated with very high levels. ${ }^{6}$ Therapy and follow up also have a role in establishing the diagnosis. Good response to ATT confirmed by endoscopic and histological clearance of disease confirms the diagnosis of TB. Conversely, a poor response to ATT suggests either drug-resistant TB or CD. ${ }^{7}$ In our patient, treatment for Crohn's disease was initiated due to chronicity, growth failure, very high levels of fecal calprotectin and occasional non-caseating granuloma with negative AFB stain. Direct visualization of the gastrointestinal mucosa by endoscopy and histopathological examination establishes a diagnosis in $\mathrm{CD}$. The decision to withhold ATT in a child with a chronic gastrointestinal inflammatory disorder in India with a high prevalence of tuberculosis is difficult, especially in ambiguous cases. ${ }^{7}$

\section{Compliance with Ethical Standards \\ Funding: None \\ Conflict of Interest: None}

\section{References :}

1. Epstein D, Watermeyer G, Kirsch R. The diagnosis and management of Crohn's disease in populations with high-risk rates for tuberculosis. Aliment Pharmacol Ther. 2007;25:1373-88.

2. Jones DA, Guha K, Ho TB. Notification of tuberculosis in an area of low TB incidence. Clin Med (Lond). 2008;8:637

3. Wong WM, Lai KC, Yiu WC, Wong BC, Chan FL, Lai CL. Intestinal tuberculosis mimicking fistulizing Crohn's disease. J Gastroenterol Hepatol. 2007;22:137-9.

4. Pulimood AB, Amarapurkar DN, Ghoshal U, Phillip M, Pai CG, Reddy DN, et al. Differentiation of Crohn's disease 
from intestinal tuberculosis in India in 2010. World J Gastroenterol. 2011;17:433-43.

5. Makharia GK, Srivastava S, Das P, Goswami P, Singh U, Tripathi M, et al. Clinical, endoscopic, and histological differentiation between Crohn's disease and intestinal tuberculosis. Am J Gastroenterol. 2010;105:642-51
6. Bjarnason I. The use of fecal calprotectin in inflammatory bowel disease. Gastroenterol Hepatol (N Y). 2017;13: 53-56.

7. Sindgikar SP, Shenoy RD, Shenoy V, Shankar R. Intestinal tuberculosis and Crohn: A clinician's diagnostic dilemma. Egyptian Pediatric Association Gazette. 2016;64:50-2. 